\title{
Mainstreaming Human Immunodeficiency Virus (HIV) Insurance in India: Opportunities and Challenges
}

\author{
M Trivedi and A V Raman
}

\begin{abstract}
Millions of Indians fall into poverty because of the private high Out of Pocket pattern of health financing, due to the absence of insurance coverage. Conditions like HIV and AIDS also influence poverty due to a lifelong treatment requirement. Access to insurance coverage (commercial or voluntary) has been denied to People Living with HIV (PLHIV) through various clauses. However lately, there have been certain experiments on inclusion of HIV into new or existing schemes. This paper provides a systematic review of coverage, managerial and financial systems of selected cases of HIV insurance pilots in India with an objective to explore its sustainability and ability to be replicated.
\end{abstract}

A cross-sectional descriptive analysis of existing literature and in-depth case studies of relevant health insurance schemes were used for the review. Data was compiled using qualitative data collection tools such as in-depth interviews with officials. The schemes were analysed using two frameworks viz. managerial ability and coverage ability. The managerial ability was analysed through a Strength-Weakness-OpportunityThreat (SWOT) analysis. The coverage ability was analysed through three dimensions viz. a) breadth b) depth and c) height. In India, there are two types of insurance policies vis-à-vis HIV coverage. These were categorised as HIV-specific and HIV-sensitive policies.
Of the seven pilot schemes reviewed, the small-scale health insurance schemes show limited success owing to smaller pool and limited managerial capabilities. The large schemes offer avenues for mainstreaming but pose issues of governance as well as marketing among PLHIVs. The findings of the research identify a specific set of issues and challenges for sustainability and replication from three perspectives viz. a) market, b) cost recovery and sustainability and c) equitable coverage.

Abbreviations: AIDS - Acquired Immune Deficient Syndrome; ART - Anti-retroviral Therapy; BPL - Below Poverty Line; FF-HIP - Freedom Foundation Health Insurance Policy; HIV - Human Immunodeficiency Virus; IRDA - Insurance Regulatory and Development Authority; NGO - Non Government Organisation; PLHIV - People Living with HIV; OI - Opportunistic Infections; OOP - Out of Pocket; RSBY - Rashtriya Swasthya Bima Yojana; STI - Sexually Transmitted Infection; SWOT - Strengths, Weaknesses, Opportunities, Threats; UHC - Universal Health Coverage; UNDP - United Nations Development Program.

Key words: health Insurance; Human Immunodeficiency Virus; equity; sustainability.

\section{Mayur Trivedi}

Associate Professor

Indian Institute of Public Health

Gandhinager, India

\section{Correspondence:}

mtrivedi@iiphg.org

\section{Introduction}

India's health situation, although improved over time, remains a major cause of concern compared to other industrialising countries. Owing to a demographic transition, India has witnessed an increasing proportion of young population over the last few decades and this scenario is likely to continue for another two decades or so. [1] This is particularly important, as the young population is vulnerable to Sexually Transmitted Infections (STI), including Human Immunodeficiency Virus (HIV). India continues to 
have a reasonably high burden of HIV infection and a related condition called Acquired Immune Deficient Syndrome (AIDS). [2] India does not have a generalised epidemic, and in comparison with many southern and eastern sub-Saharan African countries, it has a lower HIV prevalence as well. According to latest available estimates, India had an adult HIV prevalence of $0.26 \%$ or around 2.11 million People Living with HIV (PLHIV) in 2015. [2] In relative terms, the burden of HIV in India may not seem very high, but in an absolute sense, the burden of more than two million individuals is significant. HIV has spread widely across various states and across various sections of the population in India, and has been recognised as the most important public health issue in recent times. [3-5] The decreasing mortality and yet continuing incidence of HIV infection indicates that an increasing number of people are going to need treatment and care over time. [6-8]

There is no cure for HIV infection. However, there is a therapy called anti-retroviral therapy (ART) through which the infection can be managed. The ART includes provision of drugs and medicines, laboratory examinations including measurement of performance of immune system in terms of CD4 count - a lab test that measures the number of CD4 T lymphocytes (CD4 cells) - and medical as well as psychological consultation. Since its commencement in 2004, India's free ART programme has grown steadily. By 2014, it had expanded to cover more than 850,000 eligible patients through more than 400 ART centres across the country. [2] Despite the availability of free ART, poor families need to spend Out-of-Pocket (OOP) to meet health expenses arising out of treatment of certain opportunistic infections, including hospitalisation. There has been evidence of PLHIV facing financial burden while seeking treatment therapy under the government programme. [9-14]

The linkages between high spending on health and its effect on poverty - in terms of pushing many people below the poverty line, and affecting the living status of households who are already poor - are well established. [15-18] While on one hand, the catastrophic expenses arising out of hospitalisation in the absence of health insurance coverage have also been well documented, [19-21] people living with chronic conditions, whose spending is mostly outpatient in nature, are also vulnerable to the effect of rising OOP expenditure. [22] Although chronic conditions are largely associated with non-communicable diseases, the financial implications of communicable diseases like HIV and AIDS also influence poverty in a similar manner. While the impact of poverty on increased vulnerability to HIV infection has been debated, [23-25] the household level socio-economic impact of the infection has been well documented. [14, 26-28]

The OOP - due to lack of health coverage - is experienced by everyone, but the access to commercial or voluntary health coverage by purchasing health insurance at a premium has been denied to PLHIV in India through various clauses of different insurance policies.

These exclusions are of two types, a) pre-existing conditions, and b) permanent exclusions. The pre-existing conditions clause refers to those conditions that existed at the time of enrolment. The permanent exclusion clause is for certain conditions that are excluded 'forever'from the list of benefits, irrespective of the time of their occurrence.

STls including HIV are one such 'permanent exclusion'. While the exact wording for such exclusions can vary across policies, one of the mainstream health insurance policy reads as follows: 'Sexually transmitted diseases, any condition directly or indirectly caused due to or associated with Human T- Cell Lymphotropic Virus Type III (HTLB-III) or Lymphotropathy Associated Virus (LAV) or the Mutants Derivative or variation Deficiency Syndrome or any syndrome or condition of a similar kind commonly referred to as AIDS'. Certain preexisting chronic diseases like diabetes are covered in selected health insurance policies either after a waiting period or with additional premiums. Such coverage is almost nonexistent for HIV-related conditions.

The situation of health insurance for HIV in India has evolved over time. The discourse around insurance for HIV changed in the 2000s because of a) successful scale up of free ART programme, b) stabilisation of incidence of HIV cases, and c) emerging global debate on universal health coverage and the rollout of state and nation-wide government funded health insurance schemes.

HIV coverage in India started in schemes that provided employment-based coverage. The social health protection schemes like the Employee State Insurance Scheme, Central Government Health Scheme and organisations like the Railways and Defence, were providing all HIV care, including free access to ART. [29] However, such coverage was by default rather than design. With very limited coverage and in the absence of a free ART programme till 2004, the advocacy for mainstreamed financial coverage for HIV started with focus on covering ART for those outside the net of such schemes. During the 1990s and the first half of 2000s, along with advocacy for coverage by activists and researchers, there were also discussions within the insurance industry to start learning about the epidemic so as to prepare for product development. [30] 
Despite the changing nature of favourable discourse about insurance for HIV, there remained a denial of coverage by the mainstream commercial insurance schemes. [31] As a result, a number of pilots were initiated to demonstrate the possibility of such coverage.

These included a) Freedom Foundation Health Insurance Policy (FF-HIP), b) Karuna Trust health insurance scheme, c) Aarogyasri scheme, d) Yeshasvini Co-operative Farmers Health Care Scheme, e) Mukhya Mantri Jeevan Raksha Kosh Yojana (MMJRK), f) Rashtriya Swasthya Bima Yojana, (RSBY), and g) Star Health Insurance Netplus health insurance scheme.

Of these seven schemes, the first two schemes were pilot projects initiated by United Nations Development Programme (UNDP). The next were three (c-e) were statelevel schemes from Andhra Pradesh, Karnataka, and Rajasthan states, respectively. The RSBY is a Pan-Indian health insurance scheme for low-income sections of the society. Lastly, the Star Netplus health insurance scheme was exclusively offered to a group of PLHIV in partnership with a Non-Governmental Organisation (NGO) called Population Service International Connect.

This paper provides a comparative analysis of the abovementioned seven insurance schemes from the perspective of their coverage as well as management potential.

\section{Methods}

This is original research that involved cross-sectional descriptive analysis of existing literature and in-depth case studies of relevant health insurance schemes. The data sources were a review of secondary data, observation, and interviews with managers of the schemes. Two major objectives were a) to review the managerial and financial systems of selected cases of HIV insurance schemes in India, and b) to explore their efficacy, sustainability and ability to be replicated. An in-depth review was carried out based on case studies of each scheme, comparing their unique features and using an analytical framework. The schemes were analysed from two broad perspectives. a) managerial ability, and b) coverage ability. The managerial ability was analysed through a SWOT (StrengthWeakness-Opportunity-Threat) tool. The internal environment of the schemes was analysed to understand their strengths and weaknesses and the analysis of the external environment yielded opportunities and threats to these kinds of schemes. The coverage ability was analysed through the three dimensions of Universal Health Coverage (UHC), a) breadth i.e. the magnitude of the population that is covered, b) depth which includes the extent or scope of various health services that are covered, and c) height in terms of the level of financial protection or sum insured amount offered in the coverage. A framework was developed to analyse the coverage ability of various schemes.

The framework involved a set of sub-components across the three UHC components. These sub-components, used as variables for analysis, were given weights that were applied to these variables/scores to quantify the performance of schemes across the three dimensions. This ultimately helped arrived at a UHC index. The details of variables and their scores are described in Table 1. Assessment of managerial and coverage ability through a SWOT and UHC analysis is original research, and adds to existing knowledge.

Table 1: Framework for analysis and weighted scores of components

\begin{tabular}{|l|l|c|}
\hline UHC COMPONENT & SUB-COMPONENT OF UHC & SCORE \\
\hline Depth of coverage In terms of scope of services & Outpatient services & 1 \\
& Inpatient services & 1 \\
& Operative procedures & 2 \\
& STI treatment & 1 \\
& OI treatment & 1 \\
& ART & 2 \\
Height of coverage In terms of scope of financial protection & Maternity benefits & 1 \\
\hline Breadth of coverage In terms of scope of population coverage & Choice of providers & 3 \\
& Less than Rs. 100,000 per annum & 6 \\
\hline
\end{tabular}




\section{Analysis}

A brief description of seven cases is provided below before analysing them from a coverage and managerial ability perspective.

\section{Freedom Foundation Health Insurance Policy}

Freedom Foundation (FF) initiated a two-year pilot project in 2006, to explore the feasibility of offering an insurance scheme for PLHIV to cover their medical expenses including cost of ART, Opportunistic Infections (OI) management, and periodic testing including CD4 counts, on a graduated cost recovery model. All above-mentioned services were provided to all ART-eligible individuals visiting FF, Bangalore by a team of experienced healthcare providers. A Health Insurance Policy (HIP) was offered as a joint venture with the UNDP, in which the foundation acted both as insurer and service provider.

Under the scheme, the insured clients were to receive the coverage benefits - up to a total sum insured of Rs. 13620 (US\$ 227) per year at a payment of stipulated premium, which were on a sliding scale based on economic categories. Only sixty-nine people were enrolled as against the target of 158 individuals who were ART-eligible because of their CD4 counts. Overall, against the total premium collection of Rs. 301,002, (US\$ 5017), the corresponding claim amount was Rs. 433,257. (US\$ 7221). Despite having a good adherence and treatment follow-up, the scheme was withdrawn at 19 months, despite the original plan of 24 months. The main reason for the withdrawal was the financial nonviability of the scheme, which is attributed to an inability to recruit enough clients to the scheme. The foreclosure report indicated three major reasons for this: a) lack of awareness about health insurance, b) financial constraints, and c) availability of the free government ART programme. [32]

\section{Karuna Trust Experiment}

Karuna Trust has offered a health insurance scheme in association with UNDP and the National Insurance Company during 2002-2005. This scheme was targeted towards the poor, and offered free hospitalisation coverage at the stipulated government facilities.

The annual premium of Rs. 30 (US\$ 0.5) was subsidised for various sections of society. The scheme had a component of no-exclusion, and thus, was one of the first Community Health Insurance schemes to have covered 'all illnesses' including pre-existing conditions.

In this context, by virtue of no-exclusion, HIV-related illnesses were also covered under the policy. However, with very limited coverage amount, costly ART treatments or monitoring tests were not covered. In 2006, UNDP and Karuna Trust extended their partnership to mainstream HIV intervention in primary care, and covered 'some investigations as well as treatment of Ols'. [33] Under the scheme, HIV was being mainstreamed in primary health care and included a novel concept of offering PHC Voluntary Counselling and Testing Centres. The extended scheme also went on to cover more than 49,000 people by July 2007 . The scheme also reimbursed Rs. 2,99,400 (US\$ 4990) towards claims. [34] The UNDP partnership with Karuna trust ended in 2007. There is lack of documentation or evaluation of this scheme.

\section{Star Netplus Health Insurance}

A private health insurance company - Star Health and Allied Insurance Co. Ltd - has offered an insurance product aimed at PLHIV since July 2007. The group policy offered coverage to all HIV positive individuals who were yet to reach the AIDS stage. The 'Star HIV Care Policy' offered critical illness coverage, in which the insured person received limited monetary assistance against the onset of a pre-decided event. [35] From 2008, a partnership between PSI Connect and Star Health initiated a pilot project through which a composite policy with both lump sum payments as well as hospitalisation benefits were developed as a part of the single coverage. On one hand, while the insured were given a choice of providers, the project also made efforts to sensitise more than 1000 hospitals.

However, It offered enrolment only to a group of around 200 PLHIV, a condition that left individual aspirants out of the coverage. As a promotion, the scheme had a subsidy component wherein 50 per cent premium for the base product was provided through USAID funds under the Connect project. From a modest beginning of an annual enrolment of 256 PLHIV in 2008, the scheme went on to cover more than 7000 PLHIV in 2010. It was estimated that the aggregate claim rate under the scheme was 11 per cent and average claim of Rs. 4,954 (US\$ 83). [35] Although the partnership between Star Health and Project Connect ended in 2011 , this scheme is still functional with revised coverage.

\section{State Sponsored Large Scale Schemes}

As discussed earlier, several government-sponsored schemes operate in India. Most of these schemes contribute to the larger goal of universal coverage. Among these, a major state-level health insurance initiative is the Rajiv Aarogyasri $\mathrm{CHI}$ Scheme (Aarogyasri) of the Andhra Pradesh government. Functional since 2007, the scheme caters for around 65.4 million poor people across the state. The scheme is free to beneficiaries as the state government pays the premium to 
the designated insurance company. [36] Aarogyasri had an inclusion clause in the scheme that ensured that 'treatment for all the identified diseases, including HIV and Hepatitis-B related conditions' are covered by design. [37] The scheme offers coverage of tertiary care of 938 predefined treatment and follow-up packages.

Another ambitious government-sponsored scheme, RSBY was launched in 2008. The scheme is being offered in 25 states in partnership with insurance companies to provide financial coverage from hospitalisation expenses up to Rs. 30,000 (US\$ 500) per family per year, who has opted to become a member by paying Rs. 30 (US\$ 0.5) for the membership.

The entire premium is paid jointly by the central and state governments. In RSBY, HIV was excluded in during the first year. Later on, from the second year onwards, it was removed from the list of conditions that are permanently excluded. [38]

Both these schemes are meant only for the population owning a Below Poverty Line (BPL) card - an identity proof issued by government to poorer sections of society. This means that individuals who are HIV positive but do not possess a BPL card are not covered. To the best of author's knowledge, currently, there are no estimates on the proportion of PLHIV who are also BPL cardholders. This makes the coverage of HIV positive people in government sponsored schemes more debatable.

A similar large-scale scheme is Yeshasvini Cooperative Farmers Health Care Scheme in Karnataka. The scheme started in 2003 and offers coverage to more than three million beneficiaries against specified surgeries and procedures. It is open only to registered members of the specified cooperatives in the state. Started with a premium of Rs. 60 (Us\$1) per year per person, the scheme as of 201112 operates at an annual premium of Rs.160 (US\$3) per member. This self-funded scheme does not have insurance coverage from any insurance company; it is operated by the Yeshasvini Trust, and a TPA called 'Medi Assist India TPA Pvt. Ltd.' is the risk-bearer entity. It covers free consultations, diagnostics at discounted rates, and over 1700 types of operations. Although not designed in the original plan, the scheme currently does not exclude HIV positive individuals. Since 2008, Yeshasvini coverage has been extended to all pregnant women who are found to be HIV positive during their antenatal check-ups. ${ }^{1}$

\footnotetext{
1 See circular no. NRHM/MCH/61/08-09, at http://karhfw.gov.in/ nrhm2/7.pdf, [accessed August 3, 2011].
}

Even before the Gol free ART programme, Rajasthan provided partial funding for ART for specified poor patients through the Chief Minister's Relief Fund in Rajasthan. [39] Even after penetration of Gol's free ART programme, Rajasthan continued to offer HIV coverage through the MMJRK. Launched in January 2009 for the BPL families, the scheme aims to provide free secondary and tertiary health services. The coverage includes all kinds of inpatient as well outpatient services, conveyance, largely through government hospitals and selected thirty-two private hospitals. Although not included as a fundamental design of the scheme, in December 2009 PLHIV were accorded BPL status, and thus made beneficiaries of the scheme. [40] According to an official from the Rajasthan State AIDS Control Society, more than 12,000 patients have benefited from the scheme during April-December. [41] Details of these seven schemes are summed-up in Table 2.

The seven schemes (cases) can be broadly classified into two categories, HIV-sensitive policies and HIV-specific policies. The HIV-sensitive policies include schemes that already exist but have been modified to include PLHIV and also schemes that have been developed to proactively include PLHIV, along with other communities. The HIV-specific policies are insurance schemes that are exclusively developed for and cater to PLHIV. Of the seven schemes described above, FFHIP and Star Netplus schemes are examples of HIV-specific policies, and the remaining five are categorised as HIVsensitive policies that cater for other vulnerable groups as well. The two groups of schemes were analysed from managerial ability and coverage ability perspectives. The managerial ability was analysed through a SWOT analysis. The coverage ability was analysed through the lens of three dimensions of UHC, a) breadth, b) depth and c) height, as discussed earlier.

\section{Managerial ability - SWOT Analysis}

The SWOT analysis of HIV-specific policy is summarised in Figure 1. The various strengths of the HIV-specific schemes include a) motivation of the promoters, b) customised products, c) choice of providers with technical competency to treat HIV related complications, and d) community action/ involvement. The biggest strength of HIV-specific schemes is the high level of motivation by the promoters of the schemes. The efforts of Freedom Foundation and Star Health resulted in the evolution of first-of-its kind of schemes that provided tailor-made features. Schemes like FF-HIP featured in-house clinical care by a medical team that has been offering care over many years. On the other hand, Star can ensure access to quality clinical care with a Netplus scheme with a free choice 
Table 2: Comparison of schemes covering PLHIV in India ( Adapted from (Trivedi and Gupta 2012)

\begin{tabular}{|c|c|c|c|c|c|c|c|c|}
\hline \multirow{2}{*}{ PARAMETERS } & \multirow{2}{*}{$\begin{array}{l}\text { DETAILS OF } \\
\text { THE SCHEME }\end{array}$} & \multicolumn{7}{|c|}{ SCHEMES } \\
\hline & & $\begin{array}{l}\text { KARUNA } \\
\text { TRUST }\end{array}$ & $\begin{array}{l}\text { FREEDOM } \\
\text { FOUNDATION }\end{array}$ & $\begin{array}{c}\text { STAR } \\
\text { NETPLUS }\end{array}$ & RSBY & AAROGYASRI & YESHASVINI & MMJRK \\
\hline \multirow[t]{3}{*}{ Who are covered } & All PLHIV & & & & & & & Ö \\
\hline & BPL PLHIV & Ö & & & Ö & Ö & Ö & \\
\hline & Stage specific PLHIV & & Ö & Ö & & & & \\
\hline \multirow{8}{*}{$\begin{array}{l}\text { What benefits are } \\
\text { are covered }\end{array}$} & Outpatient services & Ö & & & Ö & Ö & Ö & Ö \\
\hline & Inpatient services & Ö & Ö & Ö & Ö & & & Ö \\
\hline & Operative procedures & Ö & Ö & Ö & Ö & Ö & Ö & \\
\hline & STI treatment & Ö & Ö & Ö & Ö & & & Ö \\
\hline & Ol treatment & Ö & Ö & Ö & Ö & & & Ö \\
\hline & ART & & Ö & & & & & \\
\hline & Maternity benefits & & & & Ö & & Ö & Ö \\
\hline & Choice of providers & & & Ö & Ö & Ö & Ö & \\
\hline $\begin{array}{l}\text { What cost is } \\
\text { covered }\end{array}$ & $\begin{array}{c}\text { Sum insured amount } \\
\text { (Rs.) }\end{array}$ & $\begin{array}{c}\text { Rs. } \\
30,000\end{array}$ & $\begin{array}{l}\text { Rs. } \\
13620\end{array}$ & $\begin{array}{l}\text { Rs. } \\
30,000\end{array}$ & $\begin{array}{c}\text { Rs. } \\
30,000\end{array}$ & $\begin{array}{c}\text { Rs. } \\
200,000\end{array}$ & $\begin{array}{c}\text { Rs. } \\
200,000\end{array}$ & Unlimited \\
\hline
\end{tabular}

of providers. This enabled the insured to access providers who were expert in treating HIV-related illnesses. Lastly, being schemes which were run either by a care and support organisation or through a network of positive people, they ensured community linkages and actions through group formation and community involvement.

The weaknesses of such schemes include a) small pool of beneficiaries, b) no or little risk pooling, c) limited financial protection, d) high premium-low coverage mix, and e) low sustainability. HIV-specific schemes, being diseasespecific schemes, offer a limited scope of pooling in terms of magnitude of members and risks. With limited pooling and mandates to cover expensive treatment, these schemes rely on a) higher premiums b) selection of coverage, and c) subsidies. Both FF-HIP and Star Netplus schemes offered limited financial protection (up to Rs. 30000 or Us\$ 500) to selected individuals (eligible in terms of CD4 counts), and had to rely on subsidies (UNDP and USAID, respectively) to make the premium affordable. This resulted in poor sustainability and limited commercial viability of such schemes like FF-HIP, especially in absence of donor funds.

\section{Figure 1: SWOT framework for HIV-specific policies}

\begin{tabular}{|l|l|}
\hline \multicolumn{1}{|c|}{ STRENGTH } & \multicolumn{1}{c|}{ WEAKNESS } \\
\hline $\begin{array}{l}\text { Motivation of the promoters } \\
\begin{array}{l}\text { Customised products } \\
\text { Technical competency of the providers } \\
\text { Community action/involvement }\end{array}\end{array}$ & $\begin{array}{l}\text { Small pool of beneficiaries } \\
\text { No or little risk pooling } \\
\text { Low sustainability } \\
\text { High premium-Low coverage mix } \\
\text { Limited financial protection }\end{array}$ \\
\hline $\begin{array}{l}\text { Knowledge generation (Evidence) } \\
\text { Advocacy - Adoption by insurance cos. } \\
\text { and funding agencies } \\
\text { Community mobilisation }\end{array}$ & $\begin{array}{l}\text { Depleted funding from development partners } \\
\text { Cream skimming } \\
\text { Partnership issues } \\
\text { Poor interest among insurer } \\
\text { Poor interest among providers }\end{array}$ \\
\hline
\end{tabular}


The opportunities of HIV-specific schemes are three-fold, viz. a) knowledge generation, b) advocacy for product innovation and c) community mobilisation. Looking at the external factors, the biggest contribution these schemes provided was new evidence on the experience of covering HIV-related expenses through a health insurance mechanism. These schemes provided data on illness profiles, treatment seeking and health expenditure. Such data can feed into the actuarial calculation and provide opportunities for product development in the long run. Similarly, these schemes provided avenues of renewed and sustained advocacy for coverage for HIV by being pioneers in the field. The data and advocacy can influence policymakers to incorporate health insurance in the realm of care and support policies. Lastly, the evidence of performance of schemes, in terms of claims rate and average claim amount, can also generate interest among insurance companies as well as funding agencies to support mainstreaming of HIV into commercial health insurance.

The threats to such schemes include a) depleted funding from development partners, b) cream skimming among insurers, and c) partnership issues with insurer and providers. The reliance on outside funding to support the premium remains the biggest threat for HIV-specific schemes; reduced funding can seriously harm the very existence of such schemes.

Another threat remains with cream skimming; insurer and provider tend to choose relatively low-risk clients leaving the end-stage PLHIV out of the pool. This means there may be a tendency to choose relatively healthier HIV cases (with higher CD4 count) while not insuring and treating the AIDS cases (with lower CD4 count). Finally, in the absence of a policy mandate, important stakeholders, i.e. risk-bearers like insurance companies and healthcare providers, can opt-out of partnerships. This can affect the performance as well as sustainability of the schemes.

A similar SWOT analysis on HIV-sensitive policies, i.e. the remaining five schemes that covered PLHIV along with other vulnerable populations, is outlined in Figure 2. The most positive outlook of HIV-sensitive schemes is their mainstreaming nature, which does not discriminate based on a person's HIV status. These schemes treat HIV like any other conditions and provide a case for an ideal way of mainstreaming HIV into existing coverage options. Second, they offer a wider pooling, both in terms of number of members as well as their risks. With the exception of Karuna Trust, all other HIV-sensitive schemes are population-wide schemes spread across the states, and ensure coverage to entire family irrespective of their risks. The large pool, as well as government sponsorship, reduced the premium to very low or nil in the majority of cases, which makes the schemes affordable to the entitled. The component of government ownership in such schemes makes them sustainable, at least in short to medium term. Lastly, unlike HIV-specific policies, HIVsensitive policies cover HIV unrelated conditions as well, and thus offer diversified and holistic coverage.

While being all-inclusive is a strength of HIV-sensitive policies in terms of being nondiscriminatory, the same characteristic also result in one of the weaknesses. Unlike HIV-specific schemes, HIV-sensitive schemes are not tailor-made and thus, may not cover, for example, certain expensive treatments. Another weakness of such schemes is the fact that PLHIV not owning a BPL card may not get covered in most schemes. Since the enrolment is based on owning a BPL card, poor PLHIV, in the absence of such card, may be excluded.

\section{Figure 2: SWOT framework for HIV-sensitive policies}

\begin{tabular}{|l|l|}
\hline STRENGTH & WEAKNESS \\
\hline $\begin{array}{l}\text { Mainstreaming } \\
\text { Large pool- greater pooling }\end{array}$ & $\begin{array}{l}\text { Coverage may not be need-specific } \\
\text { Gustainability } \\
\text { Affordable premium } \\
\text { Diversification of coverage }\end{array}$ \\
\hline OPPORTUNITY & $\begin{array}{l}\text { Eligibility - non-BPL are excluded } \\
\text { Competency of providers }\end{array}$ \\
\hline $\begin{array}{l}\text { UHC } \\
\text { Pro-poor }\end{array}$ & THREATS \\
Linkages with other govt. programmes & Poor marketing among PLHIV \\
Advocacy for funding for non-BPL PLHIV & Change in government insurance policy \\
\hline
\end{tabular}


Similarly, these schemes often have governance issues in terms of improper implementation at enrolment as well as utilisation levels. Finally, at least in the case of Karuna Trust and MMJRK scheme of Rajasthan, there is no choice of provider and benefits are largely available from public sector facilities only. Providers catering to the general population may not be oriented towards clinical as well as non-clinical needs of PLHIV, behaviours that can affect their healthcare utilisation under such schemes.

Looking at the external factors, these schemes provide an excellent platform for advocating universal coverage by ensuring that specific conditions are not excluded. Being insurance schemes for the poor, they also contribute to the argument of the poverty alleviation ability of insurance schemes, especially for diseases like HIV. HIV-sensitive schemes provided learning for linking the community to other government-sponsored health as well as social security programmes. Lastly, there is an opportunity to cover nonpoor PLHIV in such schemes, by awarding them conditional BPL status or through inviting private funding to subsidise the premium for them. Threats to HIV-specific schemes include poor marketing of such benefits to the subset of PLHIV In the community; in the environment of non-coverage, inadequate awareness of such benefits can reduce utilisation of benefits even after enrolment. In the event of a change in the stand of government policy of insurance or HIV care and support, sustainability and utility of these schemes can be jeopardised.

\section{Coverage ability --UHC analysis}

The seven schemes were analysed from the lens of three dimensions of UHC, as outlined above. Although all these schemes provided coverage for HIV, they perform differently in their characteristics in terms of coverage across breadth, depth and height. The breadth indicates the level of the population that is covered, the depth includes the extent or scope of various health services that are covered, and the height is measured in terms of the level of financial protection offered in the coverage. The performance of schemes across these dimensions was scored based on the framework and index value, as described earlier. Relative performance of various schemes across components of UHC - in the scale of one to ten - is provided in Table 3. These scores were then plotted in a Radar chart using MS-Excel for better visualisation of relative performances of schemes. These charts are presented as Figure 3-6. HIV-specific and HIV-sensitive policies perform equally in terms of depth as they cover a variety of diseases, conditions and procedures. However, HIV-specific schemes offer relatively lower coverage breadth and height and limited financial coverage. HIV-sensitive schemes, by their nature of being all-inclusive, offer wider scope of coverage across populations and across disease conditions. Thus, they have better performance in breadth and height of coverage. This comparison is illustrated in Figure 3 below.

Table 3: Three dimensions of HIV coverage: A comparison across schemes

\begin{tabular}{|l|l|c|c|c|}
\hline \multirow{2}{*}{ TYPE OF POLICIES } & \multirow{2}{*}{ PILOT SCHEME } & \multicolumn{3}{|c|}{$\begin{array}{c}\text { RELATIVE PERFORMANCE ACROSS } \\
\text { COMPONENTS OF UHC (SCORE OUT OF 10) }\end{array}$} \\
\cline { 2 - 5 } & & BREADTH & HEIGHT & DEPTH \\
\hline HIV-specific policies & Freedom Foundation & 3 & 3 & 5 \\
& Star Netplus & 3 & 3 & 6 \\
\hline HIV-sensitive Policies & Karuna Trust & 6 & 3 & 6 \\
& RSBY & 6 & 3 & 4 \\
& Aarogyasri & 6 & 6 & 7 \\
& Yeshasvini & 6 & 65 & 9 \\
& MMJRK & 9 & 9 & 7 \\
\hline
\end{tabular}

Trivedi, M. and I. Gupta (2012). “HIV Insurability in India: Early History and Current Status.” Journal of Health Management 14(4): 435-450. 
Figure 3: Three dimension of HIV coverage - a comparison across HIV sensitive and HIV specific policies

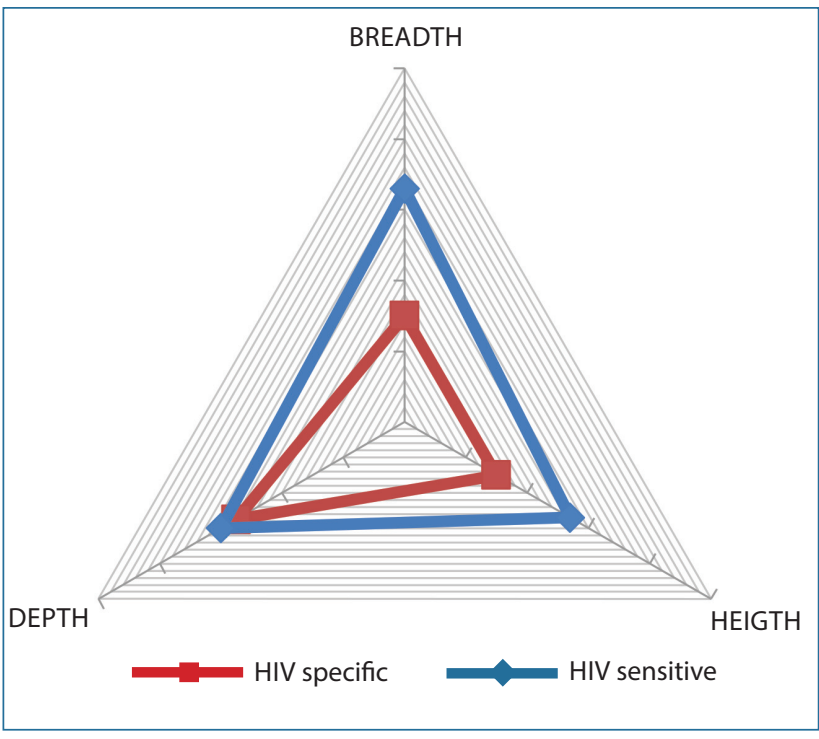

Looking at the individual schemes under the HIV-specific category, being disease-specific schemes, both FF-HIP and Star Netplus scheme have low a breadth of coverage; they offer a limited scope of risk pooling as both of them cover individuals only in late stage of infection. Star Netplus scheme covered relatively healthier PLHIV - and thus has relatively better risk pooling - but the FF-HIP lacked risk pooling altogether. Additionally, Star Netplus scheme had provision for exclusion of advanced cases of AIDS patients. This meant that the coverage for insured clients was automatically terminated once the lump sum amount at the stage of full-blown AIDS, and was not offered renewal of the hospitalisation coverage. As for the depth, i.e. the range of clinical procedures covered for management of HIV, both these schemes covered OI treatment, treatment for sexually transmitted infections, and inpatient hospitalisation. While FF-HIP covered ART and Star Netplus scheme covered operative procedures, neither of them covered maternity benefits. Both the schemes also offered very limited height of coverage i.e. highest amount that will be reimbursed under the coverage; while FF-HIP had coverage for around Rs. 13,000, (US\$ 217); the most common Star Netplus package had effective hospitalisation coverage of Rs. 15,000 (US\$ 250) only.

This is low compared with sum-insured of HIV-sensitive schemes in the range of Rs. 30,000 - 200,000 (US\$ 500-3333). Both the schemes also performed poorly on breadth and height parameters; while Star Netplus performed slightly better in terms of depth of coverage, owing especially to the fact that it offered a choice of coverage as well, the FF-HIP also performed poorly in this aspect. Across the schemes, these two score poorly in terms of universal coverage, as can be seen from Figure 4. However, the contribution of Star Netplus, in terms of generating first-of-its kind of data for actuarial calculations, is significant and generally acknowledged.

Figure 4: Three dimension of HIV coverage - comparison across HIV specific schemes

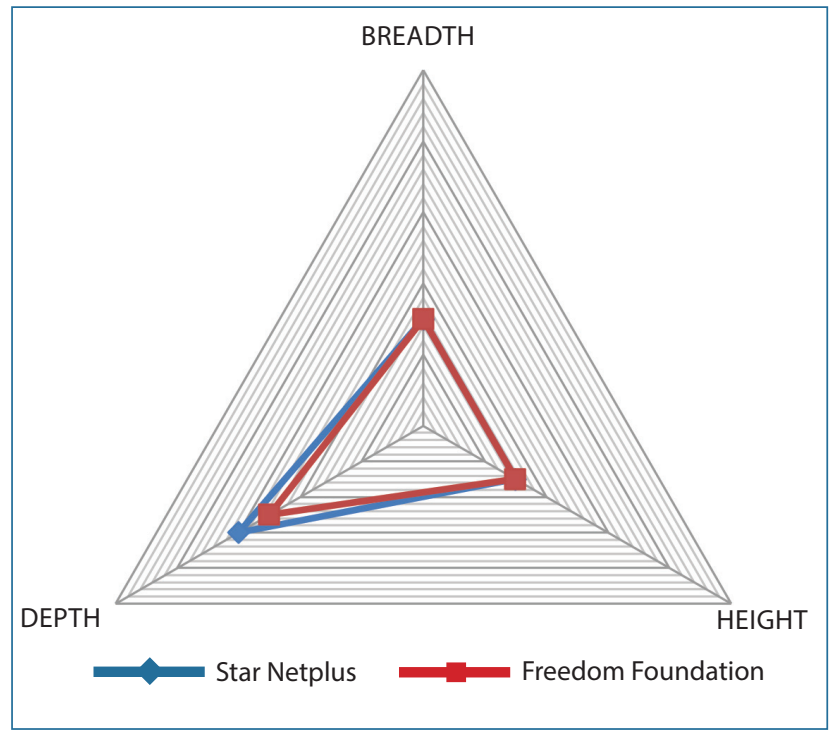

The individual schemes among the HIV-sensitive schemes were divided into two segments for UHC analysis. The first segment was schemes with moderate performance and included the Karuna Trust, Yesashvini and Aarogyasri schemes. The second segment included RSBY and MMJRK, which were top performers from the UHC perspective. Detailed analysis and description of their performance is provided below. In the first segment, all three schemes offer moderate breath of coverage as they leave out individuals who do not have a BPL card or who are not part of cooperative groups.

Karuna Trust scheme has been the frontrunner in offering coverage without any exclusions. It offers coverage to BPL populations only. Similarly, Aarogyasri as well as Yesashvini schemes offer coverage to only those who happen to be part of the specified subpopulation.

Yesashvini scheme, although covering HIV positive pregnant women, has this limitation of coverage within the specified eligibility.

As for the depth of coverage, there are differences and Karuna Trust scores higher than the two other schemes. While the former covers all clinical procedures, the latter two offer only critical illness coverage for specified surgeries and conditions, and thus, for example, do not cover Ol related hospitalisation. Among the two state-specific schemes, 
Yesashvini scores slightly better as it covers maternity benefits as a part of the convergence of National Rural Health Mission - National AIDS Control Programme initiative. As for the height of coverage, KarunaTrust scheme performed poorly with low sum-insured amount as compared to the two other schemes which had sum-insured amount of Rs. 200,000 (US\$3333). Figure 5 provides a comparison of these three schemes, which performs moderately among the seven schemes from the perspective of universal coverage.

Figure 5: Three dimension of HIV coverage: comparison across selected HIV sensitive schemes

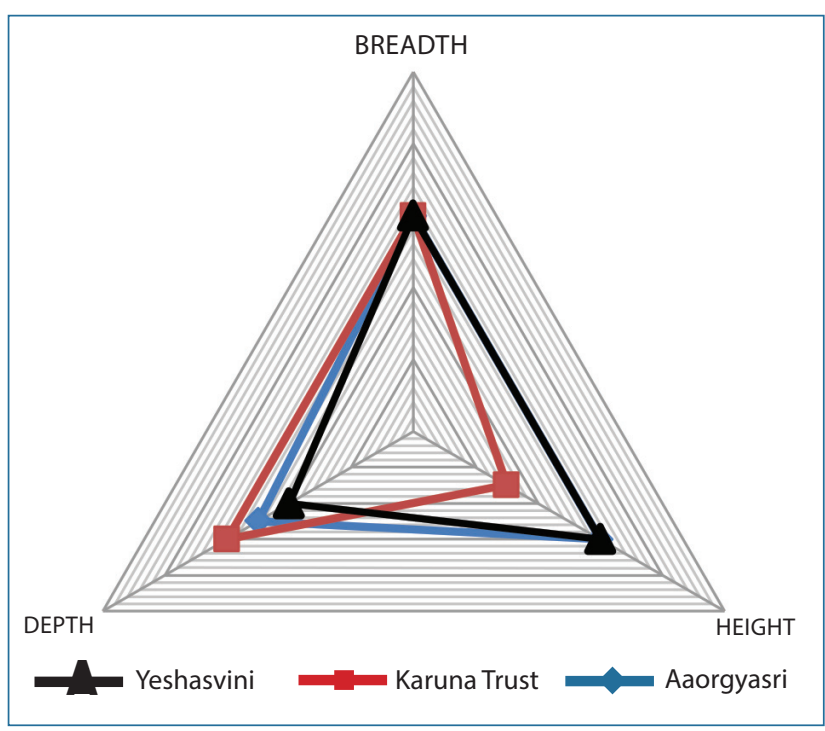

The second segment of HIV-sensitive scheme includes two top performers among all schemes i.e. RSBY and MMJRK of Rajasthan. The common factor in both these schemes was the high level of depth of coverage; both the schemes by and large covered all outpatient and inpatient services, OI treatments, STI treatments and maternity benefits.

RSBY performed slightly better in terms of depth as it offers a wider choice of providers within and outside government, as compared to its Rajasthan counterpart, where one has to rely heavily on government providers. For the other two parameters i.e. breadth and height of coverage, MMJRK scored way above RSBY. The MMJRK offered great height of coverage through unlimited amount of financial cover as compared to very limited financial coverage of RSBY. A very important breadth of coverage related initiative of MMJRK is offering PLHIV BPL status to the HIV positive population. Thus, while schemes like RSBY, Aarogyasri and Yeshasvini do not exclude HIV related conditions, MMJRK goes a step further and includes all PLHIV into the net of coverage. These characteristics make MMJRK the top performer among the seven insurance coverage schemes though relatively very high breadth and height of coverage. Figure 6 illustrates this comparison.

\section{Practice Implications}

The World Health Organisation has reiterated the need for universal health coverage, which essentially means that everyone will have access to health services and will not

Figure 6: Three dimension of HIV coverage: comparison across selected HIV sensitive schemes

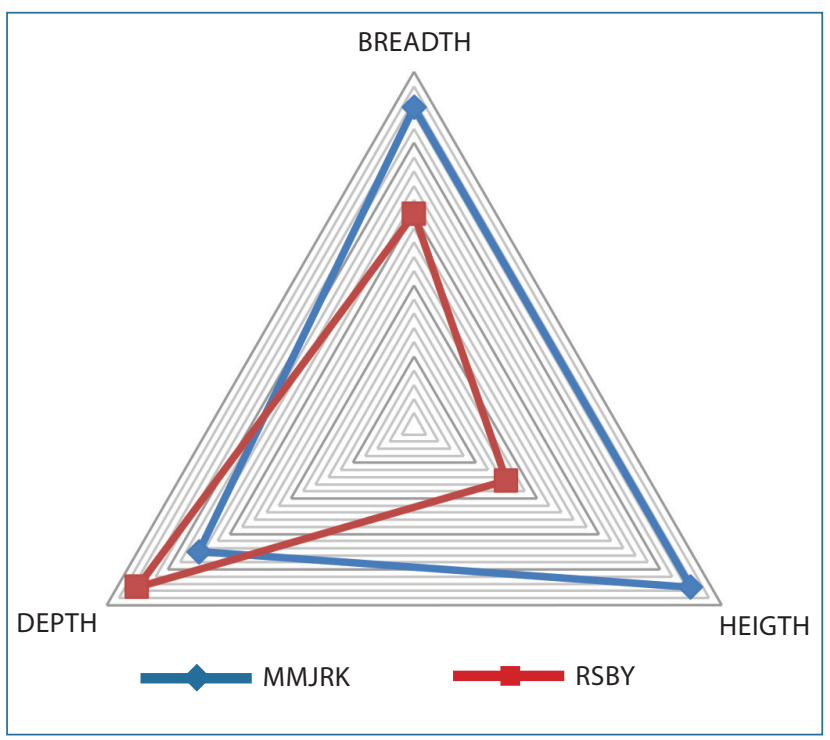

suffer financial hardships paying for them. [42] Various countries, including India, have started thinking along the lines of UHC as recommended by the WHO. Now, and especially in the light of discussions around UHC, the debate for mainstreaming HIV in insurance is being nested within the discourse on health equity and treating HIV as any other disease that impacts the poor and vulnerable to a greater extent. While there has been a great deal of debate around universal health coverage in India, there is limited discourse around the disparities in health insurance system that affect the equity and efficiency aspects of coverage in the form of excluding certain conditions.

The last decade witnessed quite a few efforts to address the issue of covering emerging diseases like HIV and AIDS. This included experiments at different levels involving commercial insurance companies, bilateral agencies, NGOs and state and national governments. These experiences have certainly generated a momentum for larger policylevel efforts to mainstream HIV in the insurance sector. This paper presented assessment of managerial and coverage abilities of seven such experiments.

Cost recovery and sustainability are interrelated and important characteristics of any insurance scheme. Small and disease-specific pools are not sustainable and are difficult to upscale and replicate. Any disease-specific schemes are against the fundamental basis of insurance and results 
have indicated the same for HIV-specific policies as well. An important finding points to the fact that a HIV-specific scheme is not the way forward.

Although HIV-specific policies offer tailor-made coverage, and provide opportunities for providing specified care through experts, these schemes suffer from issues of sustainability as they offer a limited risk and finance pooling. Most importantly, these schemes rely heavily on donor funding that is provided for administrative costs as well as subsidising the premium. Donor funding to demonstrate the possibility of health insurance coverage for HIV was essential; however, the findings indicate that this model is not sustainable on its own in the absence of such financial support.

HIV-sensitive schemes, on the other hand, promote mainstreaming and ensure pooling across various risks, but they largely exclude non-poor PLHIV. HIV-sensitive schemes are better off with larger and better pooling, and have enhanced avenues for cost recovery and sustainability in the presence of government subsidies. Such subsidies are not based on HIV infection status; they are available to economically weaker sections of society, irrespective of their disease status. This kind of provision of government subsidy promotes targeting public funds from an equity perspective as well. Thus, for the HIV positive population, there remains a trade-off between positive discrimination through getting disease-specific insurance and becoming mainstreamed to avoid negative discrimination. [43]

Advocacy efforts are occurring in a few states to provide blanket inclusion of PLHIV in the BPL list so as to enable them to access all other social protections. [44] This is based on an argument that HIV households who were poor but not necessarily in possession of the BPL card could not access benefits of many social protection schemes that were targeted only to BPL households. However, awarding disease-based conditional BPL status cannot be an equitable solution, as the BPL status has to be based on economic criteria. HIV need not be treated differently than other chronic diseases. The 'equity across diseases' argument in favour of covering HIV in existing health insurance mechanisms like other chronic diseases does not go hand-in-hand with the advocacy for awarding HIV-specific conditional BPL status to every PLHIV irrespective of their economic status.

The small-scale exclusive schemes have clearly initiated advocacy and attempted to fill the gaps in terms of data and experience in providing HIV coverage. The comprehensive government sponsored schemes offer potential for such coverage within their equity-based coverage ambit. The Insurance Regulatory and Development Authority (IRDA) issued an exposure draft in February 2012 to 'provide insurance cover to persons living with HIV and people vulnerable to HIV/AIDS, under health insurance policies of both life and non-life insurance companies'. The National AIDS Control Organisation also constituted a working group on providing health insurance to PLHIV and those vulnerable to HIV in September 2012. In February 2013 the IRDA was further directed by the Delhi High Court to act swiftly on the implementation of guidelines providing health insurance coverage for PLHIV. In 2013 the Institute of Actuaries in India released two important studies on mortality and morbidity among PLHIV, to fill the data gap in the insurance industry. Lastly, the Standing Committee on Health and Family Welfare of the Rajya Sabha recently submitted its report on the 'Human Immunodeficiency Virus (HIV) and Acquired Immune Deficiency Syndrome (AIDS) (Prevention and Control) Bill, 2014' on April 29, 2015. Among other things, the Bill stated that 'there should not be denial or unfair treatment in providing insurance cover to people living with HIV (PLHIV)'.

The findings of this research indicate that HIV-specific policies should be a preferred option. In order to improve mainstreaming, it is important that exclusions clauses in existing commercial health insurance products are removed. This will enable people - irrespective of their economic status - to purchase commercial health insurance, if they so desire. Lastly, it is important to ensure that all PLHIV who are of poor economic status are made eligible so that they are able to purchase government-sponsored health insurance.

There remain challenges for stakeholders to take the various provisions forward and make them a reality in terms of adequate enrolment and utilisation of such schemes. The government needs to play an important stewardship role to ensure that provisions made within the existing insurance system do not remain as mere tokenism.

\section{Limitations}

While seven case studies were conducted, detailed data was available for only two cases. i.e. Freedom Foundation and Star Netplus scheme. This was largely because four of these cases were government-sponsored schemes and it was difficult to get a complete set of data from any of them. Also, Karuna Trust scheme lacked documentation that was conducive to good research. Attempts were made to compile detailed data from all schemes but without any substantial success. 


\section{Competing interests}

The author declares that he has no competing interests.

\section{References}

1. Goli S, Arokiasamy P. Demographic transition in India: an evolutionary interpretation of population and health trends using 'change-point analysis'. PLoS One. 2013;8(10): e76404.

2. NACO, NIMS. India HIV estimations 2015 - Technical Report. New Delhi: Ministry of Health and Family Welfare, Government of India; 2015.

3. Jha P, Kumar R, Khera A, Bhattacharya M, Arora P, Gajalakshmi V, et al. HIV mortality and infection in India: estimates from nationally representative mortality survey of 1.1 million homes. BMJ. 2010; 340:c621.

4. Agarwal D. Public health, human rights and HIV. Issues Med Ethics. 2002 Oct-Dec: 10(4):87.

5. Pathni AK, Chauhan LS. HIV/TB in India: a public health challenge. J Indian Med Assoc. 2003;101(3):148-9.

6. UNAIDS. Global Report: UNAIDS Report on the Global AIDS Epidemic: 2010: UN Joint Programme on HIV/AIDS; 2010.

7. NACO. Annual Report 2010-11. New Delhi: Department of AIDS Control, Ministry of Health and Family Welfare; 2011.

8. NACO. Annual Report 2012-13. New Delhi: Department of AIDS Control, Ministry of Health and Family Welfare; 2013.

9. Gupta I, Trivedi M, Kandamuthan S. Recurrent costs of India's free ART program. HIV and AIDS in South Asia. 2009:191.

10. Kumarasamy N, Venkatesh KK, Mayer KH, Freedberg K. Financial burden of health services for people with HIV/AIDS in India. Indian J Med Res. 2007;126(6): 509-17.

11. Arur A, Banke K, Sulzbach S, Selvaraju V. Private sector utilisation of HIV/AIDS services and health expenditures by people living with HIV/AIDS in India: findings from five high-prevalence states. 2009.

12. Batavia A, Balaji K, Houle E, Parisaboina S, Ganesh AK, Mayer K, et al. Adherence to Antiretroviral Therapy in patients participating in a graduated cost recovery program at an HIV Care Center in South India. AIDS Behav. 2010;14(4):794-8.

13. Joglekar N, Paranjape R, Jain R, Rahane G, Potdar R, Reddy K, et al. Barriers to ART adherence and follow ups among patients attending ART centres in Maharashtra, India. The Indian Journal of Medical Research. 2011;134(6):954.

14. Pradhan B, Sundar R, Singh SK. Socio-economic impact of HIV and AIDS in India. New Delhi: United Nations Development Programme; 2006.

15. Garg CC, Karan AK. Reducing out-of-pocket expenditures to reduce poverty: a disaggregated analysis at rural-urban and state level in India. Health Pol Plan. 2009;24(2):116-28.

16. O'Hara B. Do medical out-of-pocket expenses thrust families into poverty? J Health Care Poor Underserved. 2004;15(1):63-75.

17. Van Doorslaer E, O'Donnell O, Rannan-Eliya RP, Somanathan A, Adhikari SR, Akkazieva B, et al. Paying out-of-pocket for health care in Asia: catastrophic and poverty impact. Proyecto Equitap: Documento de trabajo. 2005;2.

18. Berman PAaA R, Kalavakonda V. India Case. Global marketplace for private health insurance: strength in numbers. Washington DC: The Wold Bank; 2008. p. 327-48.

19. Gol. National Health Accounts India 2004-05. New Delhi: Ministry of Health and Family Welfare, Government of India; 2009.

20. Roy KaH DH. Equity in out-of-pocket payments for hospital care: evidence from India. Health Policy. 2007;80(2):297-307.
21. Devadasan NC B, Van Damme W, Ranson K, Van der Stuyft P. Indian community health insurance schemes provide partial protection against catastrophic health expenditure. BMC Health Services Research. 2007;7(1).

22. Kim JY, Chan M. Poverty, health, and societies of the future. Viewpoint. JAMA. 2013;310(9):901-2.

23. WHO. What is the impact of HIV on families? World Health Organisation. Regional Office for Europe, Health Evidence Network (Europe), editors. Copenhagen: WHO Regional Office for Europe; 2005.

24. Barnett T, Whiteside A. AIDS in the twenty-first century: disease and globalization: Palgrave Macmillan; 2002.

25. Parkhurst JO. Understanding the correlations between wealth, poverty and human immunodeficiency virus infection in African countries. Bulletin of the World Health Organisation. 2010;88(7): 519-26.

26. ADB and UNAIDS. Asia-Pacific's opportunity: investing to avert an HIV/AIDS crisis. Manila: Asian Development Bank; 2004.

27. Cohen D. Poverty and HIV/AIDS in Sub-Saharan Africa. New York: United Nationals Development Programme; 1999.

28. Seeley J, Zalwango F, Mugisha J, Kinyanda E, Wake C, Scholten F. Poverty, ageing and HIV in Wakiso district, Uganda. Years of the war against poverty: what we have learned since 2000 and what should we do. 2010-2020. 2010.

29. Gupta I, Roy A, Trivedi M. Access to antiretroviral treatment: what role can health insurance play in India? New Delhi: Population Council; 2004.

30. Land S. Product development in an HIV/AIDS environment. 5th Global Conference of Actuaries; New Delhi: FICCl; 2003. p. 349-79.

31. Trivedi M, Gupta I. HIV insurability in India: early history and current status. J Health Manage. 2012;14(4):435-50.

32. Freedom Foundation. Health Insurance Project - study report. 2008.

33. Ramamurthi D. High cost of treatment adds to troubles of HIV positive persons. The Hindu. Jul 31, 2006.

34. UNDP. F A C T S HE ET : Health Insurance for People Living with HIV2007: Available from: http://data.undp.org.in/factsheets/hiv/ oct07/HealthInsurance.pdf.

35. Gupta I, Trivedi M, Rudra S, Joe W, Peter B, Subbiah R. Implications and feasibility of commercial health insurance for people living with HIV in India. In: Narain JP, editor. Three decades of HIV/AIDS in Asia. New Delhi: Sage Publications; 2012.

36. Rao M, Kadam S, Sathyanarayana T, Shidhaye R, Shukla R, Ramachandra SS, et al. A rapid evaluation of the Rajiv Aarogyasri community health insurance scheme in Andhra Pradesh, India. BMC Proc. 2012;16;6 Suppl 1:04.

37. Babu A, editor. Rajiv Aarogyasri Health Insurance Scheme. Towards mainstreaming HIV in insurance: the road map and role of key stakeholders; 2011; New Delhi.

38. Palwal A, editor. Rashtriya Swasthya Bima Yojana. Towards mainstreaming HIV in insurance: the road map and role of key stakeholders; New Delhi;. 2011.

39. Acharya V, Mathur D. Accessibility to treatment helps in removing stigma and discrimination - an Indian experience. International Conference on AIDS Bangkok; 2004.

40. Nadkarni V, Goel S, Pongurlekar S. HIV sensitive social protection: a four state utilisation study. New Delhi:TISS-UNDP Collaboration; 2011.

41. Sharda P, editor. Mukhyamantri Jeevan Raksha Kosh, Rajasthan. Towards mainstreaming HIV in insurance: the road map and role of key stakeholders; New Delhi; 2011. 
42. World Health Organisation. The World Health Report: health systems financing: the path to universal coverage. Geneva: World Health Organisation; 2010.

43. Squire C. Being naturalised, being left behind: the HIV citizen in the era of treatment possibility. Critical Public Health. 2010;20(4): 401-27.

44. United Nations Development Program. Social protection that works for PLHIV: a compendium of case studies from 8 states. New Delhi: United Nations Development Programme; 2011. 